\title{
The Toxicity of Diesel Exhaust: Implications for Primary Care
}

\author{
Irina N. Krivoshto, BA, John R. Richards, MD, Timothy E. Albertson, MD, MPH, PhD, \\ and Robert W. Derlet, $M D$
}

Diesel fuel and the products of its combustion represent one of the toxins most commonly encountered by people living in both urban and rural areas of the world. As nations become more heavily populated, there will be increasing reliance on diesel fuel to power mass transportation and commercial vehicles, as well as heavy machinery involved in construction, farming, and mining. The majority of patients who present to urban primary care clinics and emergency departments will have had significant chronic exposure to diesel exhaust because most use and/or live near busy streets and highways. Furthermore, those who operate or work or live near diesel-powered machinery will have even more toxic exposure. Primary care physicians should be aware of the acute and chronic deleterious clinical effects of diesel exhaust. In this article we review the toxicity and myriad health problems associated with diesel exhaust. (J Am Board Fam Med 2008;21:55-62.)

The compression-ignition diesel engine was invented by Rudolph Diesel in 1892 as an alternative to the spark-ignition gasoline engine. ${ }^{1}$ The engine's popularity expanded because it had excellent fuel economy and durability and it required less maintenance. Diesel is the fuel of choice for use in mass transportation vehicles such as trucks, buses, and trains. Diesel fuel and the products of its combustion represent one of the most common toxins to which people living in both urban and rural areas of the world are exposed. On an equal horsepower basis, diesel exhaust is 100 times more toxic than gasoline exhaust, even when carbon monoxide is considered. $^{2}$ The Environmental Protection Agency estimates truck exhaust accounts for 20\% of all vehicle-produced microscopic soot and 30\% of all smog-causing chemicals in the United States. ${ }^{1}$ As for passenger cars, fewer than $1 \%$ of new American cars have diesel engines. In contrast,

This article was externally peer reviewed.

Submitted 31 May 2007; revised 30 July 2007; accepted 7 August 2007.

From the School of Medicine (INK), the Department of Emergency Medicine (JRR,RWD), and the Department of Internal Medicine (TEA), University of California-Davis.

Funding: none.

Conflict of interest: none declared.

Corresponding author: John R. Richards, MD, Department of Emergency Medicine, U.C. Davis Medical Center, PSSB 2100, 2315 Stockton Boulevard, Sacramento, CA 95817 (E-mail: jrrichards@ucdavis.edu). diesel engines power $37 \%$ of all new cars sold in Europe, with rates as high as $62 \%$ in France. ${ }^{3}$ One reason for this discrepancy is the suboptimal quality of diesel fuel sold in the United States; roughly half of the supply has been found to be below the standards recommended by equipment manufacturers. ${ }^{1}$

The majority of patients who present to urban primary care clinics and emergency departments may have had a potentially significant chronic exposure to diesel exhaust because many of them live near busy streets and highways. In Japan and Europe, epidemiologic surveyors have demonstrated high acute and chronic respiratory disease morbidity rates from occupational and proximity exposure to diesel exhaust. ${ }^{4}$ The National Institute for Occupational Safety and Health estimates millions of workers are occupationally exposed to the combustion products of diesel fuel in their respective workplaces. Diesel exhaust is a complex mixture of toxic compounds with wide variability of deleterious effects in human and animal studies. This represents a significant limitation to epidemiologic research on diesel exhaust because the over-reporting of exposure may affect study outcomes. ${ }^{5}$ Thus, no standard for exposure limits exists at this time.

Patients most likely to be in proximity to diesel exhaust on the job and thus suffer from occupational exposure include (1) shipping, receiving, and 
Table 1. Potential sources of clinically significant exposure to diesel exhaust

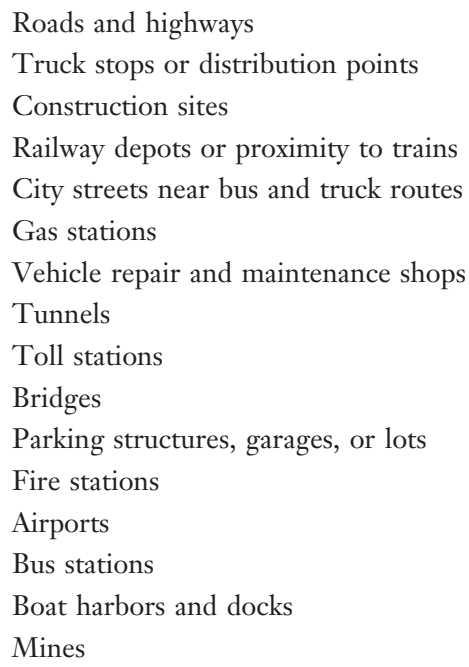

loading dock workers; (2) bus, truck, and forklift drivers; (3) railroad workers; (4) mine workers; (5) diesel engine repair and maintenance garage workers; (6) construction site, tunnel, and bridge workers. In 2006 the California Air Resources Board estimated that diesel exhaust pollution directly accounts for 2400 deaths and, annually, nearly 3000 hospital admissions for respiratory and cardiac-related diseases, at a total cost of $\$ 19$ billion. ${ }^{6}$ Besides on-the-job exposure to diesel exhaust, patients may be exposed to diesel exhaust from myriad and commonplace sources (Table 1). Primary care physicians should be aware of the acute and chronic deleterious health effects from diesel exhaust and its potential to exacerbate other chronic disease states. We thoroughly searched medical and scientific literature databases to identify those articles that specifically addressed the relationship between diesel exhaust pollution and illness. Here we review the myriad health problems associated with this commonly encountered substance.

\section{Diesel Exhaust Composition}

There are many components of diesel exhaust, including (1) carbon monoxide and carbon dioxide; (2) nitrogen oxides; (3) sulfur oxides; (4) hydrocarbons; (5) unburned carbon particles (soot); and (6) water. ${ }^{2}$ Exhaust from diesel engines is considered to contribute to more than $50 \%$ of ambient particulate matter with a mass median aerodynamic diameter less than $10 \mu \mathrm{m}$ (PM10), greatly contribut- ing to overall air pollution. For fine particulate matter with a diameter below 2.5 $\mu \mathrm{m}$ (PM2.5) and ultra-fine particles with a diameter below $0.1 \mu \mathrm{m}$, this contribution is even higher. ${ }^{1}$ These carbon particles are small enough to be inhaled and deposited in the lungs but have a large surface area. Organic compounds from diesel exhaust with known toxic and carcinogenic properties, such as polycyclic aromatic hydrocarbons (PAH), adhere easily to the surface of the carbon particles and are carried deep into the lungs. ${ }^{4}$ The majority of these particles tend to be found in the greatest concentration within the immediate vicinity of busy streets or highways. ${ }^{7,8}$ Diesel engines emit other toxic compounds in disproportionately higher concentrations than gasoline engines, including nitrogen oxides, sulfur oxides, ozone, formaldehyde, benzene, and smaller organic molecules. Diesel engines also produce $26 \%$ of the total nitrogen oxides in outdoor air. Nitrogen oxides are a major contributor to ozone production and smog. More attention has been focused on the hundreds of different types of organic molecules created from the high-compression ratios of diesel engines because many are highly toxic. ${ }^{1}$ A summary of the composition of diesel exhaust and its biological effects are detailed in Table 2.

\section{Cardiac Effects}

Acute coronary syndrome (ACS) and other thrombotic effects have been associated with acute exposure to diesel exhaust. ${ }^{9,10}$ A recent study by Mills and associates evaluated men with previous myocardial infarction who were exposed to diesel exhaust during moderate exercise. Significant STsegment depression was noted, as well as diminished release of endothelial tissue plasminogen activator. ${ }^{11}$ Possible mechanisms to explain these results include diesel exhaust-induced coronary vasoconstriction, transient thrombus formation, carbon monoxide exposure, and altered myocardial energetics. ${ }^{12}$ Another recent study of 1816 postmenopausal women with long-term exposure to air pollution, of which diesel exhaust represented a significant proportion, concluded there was an increased risk of cardiovascular disease and death proportional to the level of exposure. ${ }^{13}$ One European study group examined the association between exposure to diesel exhaust and hospital admission for ischemic heart disease in 8 cities and found that 
Table 2. Composition, breakdown, and carcinogenicity of diesel exhaust

\begin{tabular}{|c|c|c|}
\hline Gas-Phase Emission Components & Atmospheric Reaction Products & Biological Impact \\
\hline Carbon dioxide & - & Global warming \\
\hline Carbon monoxide & - & Asphyxiation \\
\hline Nitrogen oxides & Nitric acid, ozone & Respiratory tract irritants, acid rain \\
\hline Sulfur dioxide & Sulfuric acid & Respiratory tract irritant, acid rain \\
\hline \multicolumn{3}{|l|}{ Hydrocarbons } \\
\hline Alkanes & Aldehydes, alkyl nitrates, ketones & Respiratory tract irritants \\
\hline Alkenes & Aldehydes, ketones & $\begin{array}{l}\text { Respiratory tract irritants, mutagenic and } \\
\text { carcinogenic }\end{array}$ \\
\hline \multicolumn{3}{|l|}{ Aldehydes } \\
\hline Formaldehyde & Carbon monoxide, hydroperoxyl radicals & Carcinogenic \\
\hline $\begin{array}{l}\text { Higher aldehydes (eg, acetaldehyde, } \\
\text { acrolein) }\end{array}$ & Peroxyacyl nitrates & $\begin{array}{l}\text { Respiratory tract and eye irritants, plant } \\
\text { damage }\end{array}$ \\
\hline $\begin{array}{l}\text { Monocyclic aromatic compounds } \\
\quad(\mathrm{eg}, \text { toluene) }\end{array}$ & Hydroxylated-nitro derivatives & Carcinogenic \\
\hline Benzene & Nitro-PAH & Mutagenic and carcinogenic \\
\hline \multicolumn{3}{|l|}{ Particle-phase emission components } \\
\hline Elemental carbon & - & Nuclei adsorb organic compounds \\
\hline Inorganic sulfate and nitrate & - & Respiratory tract irritant \\
\hline Hydrocarbons (C14-C35) & Aldehydes, ketones, and alkyl nitrates & Unknown \\
\hline $\mathrm{PAH}$ & Nitro-PAH and nitro-PAH lactones & Mutagenic and carcinogenic \\
\hline
\end{tabular}

$\mathrm{PAH}$, polycyclic aromatic hydrocarbons; C, carbon.

patients 65 years and older had a significantly increased risk of ACS after exposure to diesel pollution. ${ }^{14}$ In a study performed in a major European city, Peters et al determined that exposure to traffic, with its high levels of diesel exhaust, was associated with the onset of myocardial infarction within 1 hour. They concluded the time spent in traffic was consistently linked with an increased risk of myocardial infarction. ${ }^{15}$

Diesel exhaust particles (DEPs) have been shown to be cardiotoxic in animal studies. Minami and colleagues demonstrated in a guinea pig model that DEPs had a negative inotropic effect, induced arrhythmias, and caused sudden cardiac death. ${ }^{16}$ Another animal study by Sakakibara et al determined that DEP-induced cardiotoxicity could not be prevented with propranolol, atropine, verapamil, diltiazem, diphenhydramine, indomethacin, superoxide dismutase, or catalase. ${ }^{17}$ Diesel exhaust induces heart rate variability, ventricular arrhythmia, a significant decrease in left-ventricular systolic pressure, and an increase in left-ventricular end-diastolic pressure in animal models. ${ }^{18,19}$ It is postulated that DEP produces superoxide radicals, which cause irreversible myocardial damage leading to cardiac arrest. ${ }^{20}$
DEPs also have been shown to induce immunoglobulin E synthesis and cause histamine release. ${ }^{21}$ Histamine is a potent coronary vasoconstrictor and platelet and thrombin activator, and it up-regulates P-selectin on endothelial cell surfaces. ${ }^{22} \mathrm{~A}$ high incidence of serious cardiac arrhythmias was noted in patients with implanted cardioverter defibrillators who had significant exposure to air pollution. ${ }^{23}$ Zanobetti and Schwartz reported that diabetics have twice the risk of ACS-related admission because of particulate air pollution exposure. ${ }^{24}$ Another study from Finland found that patients undergoing serial cardiac exercise testing had a higher incidence of ST-segment depression during days of high particulate air pollution. ${ }^{25}$ Progression of atherosclerosis has also been linked to air pollution exposure. $^{26}$

Occupational hazards may also be a factor in development of coronary artery disease. Finkelstein et al, after controlling for smoking, reported higher incidence of ischemic heart disease in heavy equipment operators chronically exposed to DEPs. ${ }^{27}$ It may then be important for primary care physicians to inquire about occupational or environmental exposure to diesel exhaust from patients presenting with chest pain and dyspnea. For patients whose 
ACS was indeed precipitated by acute exposure to diesel exhaust, it will be important to counsel them about avoiding diesel fumes in the future.

\section{Pulmonary Effects}

DEPs have been demonstrated to increase the production of inflammatory cytokines such as interleukin $1 \beta$, interleukin 8 , and granulocyte-macrophage colony-stimulating factor from cyclo-oxygenase stimulation in bronchial epithelial cells. ${ }^{28}$ This in turn results in decreased adhesion between cells, reduction of structural integrity, and inhibited repair. Pulmonary damage incurred from DEP exposure may resemble that caused by bacterial endotoxin. ${ }^{29}$ Asphyxiation from diesel exhaust is more likely to be caused by acute lung injury from soot particles, nitrogen dioxide, and sulfur dioxide than by carbon monoxide. This is different from gasoline exhaust, which contains 28 times more carbon monoxide than diesel exhaust. ${ }^{30}$ Nevertheless, in patients with significant acute and/or chronic diesel exhaust exposure, carbon monoxide levels should be checked. In the absence of deliberate exposure, elevated carbon monoxide levels may represent a marker for serious exposure to diesel exhaust and should be further investigated. Patients with reactive and/or obstructive airway diseases such as asthma and emphysema may have their underlying disease exacerbated as a result of exposure to diesel exhaust. ${ }^{31-33}$ Visits to the emergency department for pulmonary complaints have been shown to increase during periods of severe air pollution. ${ }^{34}$ One possible explanation is DEPs combining with atmospheric allergenic molecules to create even more inflammatory allergens. ${ }^{35}$ Admission rates for pediatric asthma exacerbation have been shown to be higher in areas with greater-than-average diesel emissions. ${ }^{36}$ DEPs have been shown to directly induce degranulation of mast cells with subsequent histamine release. ${ }^{37}$ Histamine release-induced by exposure to DEPs may result in allergic conjunctivitis, rhinosinusitis, pharyngitis, laryngitis, and chronic cough. ${ }^{38}$ Macrophages, the first line of immunologic defense within the lung, are severely impaired from exposure to high concentrations of DEPs, resulting in an increased risk of bacterial and viral bronchitis and pneumonia. ${ }^{39}$ Although no relevant clinical studies have been published, primary care physicians may consider the inclusion of antihistamines in addition to $\beta$-agonists and corticoste- roids for the care of patients with acute exacerbation of reactive airway disease precipitated by diesel exhaust exposure.

Many substances in diesel exhaust, such as ozone, can contribute to lung tissue destruction. Ozone is formed from nitrogen oxides, which diesel engines emit in disproportionately higher amounts compared with catalytic converterequipped gasoline engines. Many of the hydrocarbon molecules emitted by diesel engines, such as $\mathrm{PAH}$, are quite toxic to the lung. Living in areas with high DEPs accelerates pulmonary disease. Chronic exposure to DEPs is associated with an increased risk for the development of asthma. Churg et al compared postmortem lung histology of nonsmoking inhabitants of Mexico City, Mexico, with those of Vancouver, British Columbia, Canada. ${ }^{40}$ The lungs of the Mexico City inhabitants were significantly more diseased, with smaller airways consistent with an obstructive pattern and ultra-fine particles embedded in the airway mucosa. A similar study comparing young, recently deceased patients in Los Angeles and Miami found higher levels of pulmonary centriacinar inflammation in the Los Angeles residents. ${ }^{41}$ A large study of children demonstrated a significant decrease in the forced expiratory volume in 1 second (FEV1) in those patients living in areas with high concentrations of DEPs. ${ }^{42}$ Another pediatric study concluded a dose-dependent inverse association exists between the carbon content of airway macrophages and FEV1 for children living in urban areas with significant diesel exhaust exposure. ${ }^{43}$ Workers in enclosed spaces such as mines and ships are especially at risk from DEP-induced pulmonary disease. Jorgensen and Svensson reported that underground miners had productive cough and frequent respiratory infections, ${ }^{44}$ and Wade and Newman attributed asthma in train crews to diesel exhaust. ${ }^{45}$

\section{Cancer}

In 1989, the International Agency for Research on Cancer concluded that there is sufficient evidence for the carcinogenicity of diesel exhaust in experimental animals but limited evidence for carcinogenicity in humans. In 1990, California identified diesel exhaust as a substance known to cause cancer. Diesel exhaust particles have been shown to directly damage DNA and result in carcinogenesis in several animal lung studies. ${ }^{46}$ Diesel exhaust parti- 
cles have been shown to generate reactive oxygen species, which lead to oxidative stress and DNA damage. PAH associated with diesel exhaust are genotoxic, forming PAH-DNA adducts and resulting in mutation and DNA strand breakage. ${ }^{47}$ Occupational studies of railroad workers, heavy equipment operators, and truck drivers have demonstrated a significantly higher-than-normal incidence of death from lung cancer. ${ }^{48,49}$ A more recent case-control study of occupational diesel exhaust exposure in Montreal, Quebec, Canada found a limited association with lung cancer in both smokers and nonsmokers. ${ }^{50}$ Gustavsson et al reported that workers exposed to combustion products had a higher incidence of esophageal cancer. ${ }^{51}$ In a study by Guo et al, human exposure to DEPs was associated with a higher risk of ovarian cancer but not with esophageal, testicular, or urinary tract cancers or leukemia. ${ }^{52}$ A possible causal relationship between DEPs and multiple myeloma was reported by Lee et al. ${ }^{53}$

\section{Hypertension}

A link between hypertension and diesel exhaust exposure seems to exist, based on several studies. ${ }^{54-57}$ Transient hypertension has been associated with brief periods of severe pollution and is possibly related to the effect of DEPs on cardiovascular autonomic control. This sudden increase in blood pressure may be a cofactor in the development of myocardial ischemia precipitated by diesel exhaust exposure. At levels encountered in an urban environment, inhalation of dilute diesel exhaust impairs regulation of vascular tone and endogenous fibrinolysis. ${ }^{58}$

\section{Neurotoxicity}

Volatile hydrocarbons such as PAH attach to DEPs and are rapidly absorbed through the lungs into the central nervous system. A possible association between chronic DEP exposure and Parkinson's disease has been explored because DEPs have been shown to decrease the number of dopaminergic neurons in the brain tissue of mice. ${ }^{59}$ Another study group demonstrated that brain inflammation induced by DEPs resulted in histopathologic changes similar to those seen in patients with Alzheimer's disease. $^{60}$ The result of chronic DEP exposure may affect learning ability, coordination, memory, and judgment in both children and adults. ${ }^{61}$ Kilburn demonstrated slowness of response, memory loss, and disordered sleep suggestive of neurobehavioral impairment in workers whose occupations involved significant indoor diesel exhaust exposure. Abnormalities such as visual field defects, delayed blink reflex latency, and balance impairment, as well as impaired recall memory, problem solving, and perceptual motor speed tests were also detected. ${ }^{62}$

\section{Perinatal Health and Infertility}

Several worldwide studies have linked diesel exhaust exposure to low birth weight in infants, premature births, congenital abnormalities, and elevated infant mortality rate. ${ }^{63-66}$ DEPs caused a significant decrease in adult sperm production and a diminished number of Sertoli cells in an animal model. ${ }^{67}$ Other studies have shown aberration of sex hormone production and effect in chronically exposed female rats, with increased levels of testosterone and subsequent masculinization. ${ }^{68}$ Pregnant rats exposed to DEPs had higher rates of spontaneous abortions. There are few human epidemiologic studies, but one study demonstrated a negative effect of DEPs on human sperm motility. ${ }^{69}$ Another compound isolated from DEPs, 4-nitrophenol (PNP), has been identified as a vasodilator. One study group demonstrated that PNP has estrogenic and antiandrogenic activities in vivo, leading to sterility. ${ }^{70}$ The accumulation of PNP in air, water, and soil may be one factor in the increasing incidence of sterility in humans and animals, but epidemiologic studies are pending.

\section{The Future}

In 2001 the Environmental Protection Agency proposed the Heavy-Duty Engine and Vehicle Standards and Highway Diesel Fuel Sulfur Control Requirements, to be implemented by 2008. ${ }^{1}$ The production and distribution of low $(<30$ parts per million) sulfur content diesel fuel, which is widely available in Europe, is one of the most significant changes in policy. This cleaner diesel fuel is viewed as being essential to reducing tailpipe emissions from large trucks and buses; the current sulfur content prevents pollution control equipment from working properly. ${ }^{71}$ After-treatment devices such as diesel particulate filters, traps, and nitrogen oxide-reducing catalysts are also being implemented. One study found that buses using diesel and compressed natural gas as well as clean diesel fuel and 
Table 3. Unexplained signs and symptoms and potential diesel exhaust exposure

Chest pain
Arrhythmia
Dyspnea
Cough
Rhinitis
Conjunctivitis
Bronchospasm
Laryngitis
Neoplasm
Impotence
Hypertension
Headache
Dizziness
Insomnia
Memory loss
Dementia

particulate traps were superior to standard diesel buses with regard to emissions. ${ }^{72}$ A new generation of diesel engines developed for Europe should become available in the United States in the near future. The Environmental Protection Agency has issued a Notice of Proposed Rulemaking to implement onboard diagnostic systems to monitor diesel exhaust emissions on heavy-duty engines used in highway vehicles over 14,000 pounds by 2010 . Individual states are also implementing "No Idling" policies with regard to diesel-powered vehicles that are not in active use.

\section{Conclusions}

As populations continue to grow worldwide, the expansion of mass transportation and the construction of new buildings for housing and commerce will occur concomitantly. Until alternative energy sources are fully developed and implemented, reliance on diesel fuel will increase. Acute and chronic exposure to diesel exhaust will continue to be a problem in the United States. This will ultimately increase the number of patients presenting to urban primary care clinics and emergency departments with cardiopulmonary disease, neurological disorders, and adverse perinatal events. If new regulations and technology to reduce DEP emissions are fully implemented and prove to be effective, this outcome may be averted. The omnipresence of diesel exhaust in urban areas may lead the clinician to preclude its query in the patient's history. A plethora of unexplained signs and symptoms may be caused by diesel exposure (Table 3). Although no specific screening guidelines exist, primary care physicians should question patients about potential exposure to diesel exhaust and be familiar with its myriad deleterious health effects.

\section{References}

1. Gilman P. Health assessment document for diesel engine exhaust, EPA/600/8-90/057F. Washington, DC: US Environmental Protection Agency; 2002.

2. Zielinska B, Sagebiel J, McDonald JD, Whitney K, Lawson DR. Emission rates and comparative chemical composition from selected in-use diesel and gasoline-fueled vehicles. J Air Waste Manag Assoc 2004;54:1138-50.

3. Heinrich J, Wichmann HE. Traffic related pollutants in Europe and their effect on allergic disease. Curr Opin Allergy Clin Immunol 2004;4:341-8.

4. Kagawa J. Health effects of diesel exhaust emissions-a mixture of air pollutants of worldwide concern. Toxicology 2002;181-182:349-53.

5. Kuehni CE, Strippoli MP, Zwahlen M, Silverman M. Association between reported exposure to road traffic and respiratory symptoms in children: evidence of bias. Int J Epidemiol 2006;35:779-86.

6. California Air Resources Board. Emission reduction plan for ports and goods movement. Available at http://www.arb.ca.gov/planning/gmerp/march21plan/ docs/resolution_06-14.pdf. Accessed December 28, 2006.

7. Corfa E, Maury F, Segers P, Fresneau A, Albergel A. Short-range evaluation of air pollution near bus and railway stations. Sci Total Environ 2004;334-335: 223-30.

8. Cyrys J, Pitz M, Bischof W, Wichmann HE, Heinrich J. Relationship between indoor and outdoor levels of fine particle mass, particle number concentrations and black smoke under different ventilation conditions. J Expo Anal Environ Epidemiol 2004;14: 275-83.

9. Peters A, Dockery DW, Muller JE, Mittleman MA. Increased particulate air pollution and the triggering of myocardial infarction. Circulation 2001;103:2810-5.

10. Peters A, von Klot S, Heier M, et al. Cooperative Health Research in the Region of Augsburg Study Group. Exposure to traffic and the onset of myocardial infarction. N Engl J Med 2004;351:1721-30.

11. Mills NL, Tornqvist H, Gonzalez MC, et al. Ischemic and thrombotic effects of dilute diesel-exhaust inhalation in men with coronary heart disease. N Engl J Med 2007;357:1075-82.

12. Mittleman MA. Air pollution, exercise, and cardiovascular risk. N Engl J Med 2007;357:1147-9.

13. Miller KA, Siscovick DS, Sheppard L, et al. Longterm exposure to air pollution and incidence of cardiovascular events in women. N Engl J Med 2007; 356:447-58. 
14. Le Tertre A, Medina S, Samoli E, et al. Short-term effects of particulate air pollution on cardiovascular diseases in eight European cities. J Epidemiol Community Health 2002;56:773-9.

15. Peters A, von Klot S, Heier M, et al. Exposure to traffic and the onset of myocardial infarction. N Engl J Med 2004;351:1721-30.

16. Minami M, Endo T, Hamaue N, et al. Electrocardiographic changes induced by diesel exhaust particles (DEP) in guinea pigs. Res Commun Mol Pathol Pharmacol 1999;105:67-76.

17. Sakakibara M, Minami M, Endo T, et al. Biological effects of diesel exhaust particles (DEP) on isolated cardiac muscle of guinea pigs. Res Commun Mol Pathol Pharmacol 1994;86:99-110.

18. Wold LE, Simkhovich BZ, Kleinman MT, et al. In vivo and in vitro models to test the hypothesis of particle-induced effects on cardiac function and arrhythmias. Cardiovasc Toxicol 2006;6:69-78.

19. Anselme F, Loriot S, Henry JP, et al. Inhalation of diluted diesel engine emission impacts heart rate variability and arrhythmia occurrence in a rat model of chronic ischemic heart failure. Arch Toxicol 2007; 81:299-307.

20. Okayama Y, Kuwahara M, Suzuki AK, Tsubone H. Role of reactive oxygen species on diesel exhaust particle-induced cytotoxicity in rat cardiac myocytes. J Toxicol Environ Health A 2006;69:1699-710.

21. Mamessier E, Nieves A, Vervloet D, Magnan A. Diesel exhaust particles enhance $\mathrm{T}$-cell activation in severe asthmatics. Allergy 2006;61:581-8.

22. Nemmar A, Hoet PH, Vermylen J, Nemery B, Hoylaerts MF. Pharmacological stabilization of mast cells abrogates late thrombotic events induced by diesel exhaust particles in hamsters. Circulation 2004;110:1670-7.

23. Peters A, Liu E, Verrier RL. Air pollution and incidence of cardiac arrhythmia. Epidemiology 2000;11: $11-7$.

24. Zanobetti A, Schwartz J. Cardiovascular damage by airborne particles: are diabetics more susceptible? Epidemiology 2002;13:588-92.

25. Pekkanen J, Peters A, Hoek G, et al. Particulate air pollution and risk of ST-segment depression during repeated submaximal exercise tests among subjects with coronary heart disease: the Exposure and Risk Assessment for Fine and Ultrafine Particles in Ambient Air (ULTRA) study. Circulation 2002;106:933-8.

26. Suwa T, Hogg JC, Quinlan KB, Ohgami A, Vincent R, Van Eeden SF. Particulate air pollution induces progression of atherosclerosis. J Am Coll Cardiol 2002;39:935-42.

27. Finkelstein MM, Verma DK, Sahai D, Stefov E. Ischemic heart disease mortality among heavy equipment operators. Am J Ind Med 2004;46:16-22.

28. Doornaert B, Leblond V, Galiacy S, et al. Negative impact of DEP exposure on human airway epithelial cell adhesion, stiffness, and repair. Am J Physiol Lung Cell Mol Physiol 2003;284:L119-32.

29. Inoue K, Takano H, Yanagisawa R, et al. Components of diesel exhaust particles differentially affect lung expression of cyclooxygenase- 2 related to bacterial endotoxin. J Appl Toxicol 2004;24:415-8.

30. Sivaloganathan S. Death from diesel fumes. J Clin Forensic Med 1998;5:138-9.

31. Proietti L, Spicuzza L, Polosa R. Urban air pollution at the crossroads of the allergic pandemic. Ann Ital Med Int 2003;18:64-72.

32. Takizawa H. Diesel exhaust particles and their effect on induced cytokine expression in human bronchial epithelial cells. Curr Opin Allergy Clin Immunol 2004:4:355-9.

33. Holgate ST, Sandstrom T, Frew AJ, et al. Health effects of acute exposure to air pollution. Part I: healthy and asthmatic subjects exposed to diesel exhaust. Res Rep Health Eff Inst 2003;112:1-30.

34. Wilson AM, Wake CP, Kelly T, Salloway JC. Air pollution, weather, and respiratory emergency room visits in two northern New England cities: an ecological time-series study. Environ Res 2005;97:31221.

35. Takano H, Yoshikawa T, Ichinose T, et al. Diesel exhaust particles enhance antigen-induced airway inflammation and local cytokine expression in mice. Am J Respir Crit Care Med 1997;156:36-42.

36. Trasande L, Thurston GD. The role of air pollution in asthma and other pediatric morbidities. J Allergy Clin Immunol 2005;115:689-99.

37. Diaz-Sanchez D, Penichet-Garcia M, Saxon A. Diesel exhaust particles directly induce activated mast cells to degranulate and increase histamine levels and symptom severity. J Allergy Clin Immunol 2000;106: 1140-6.

38. Groneberg-Kloft B, Kraus T, Mark A, Wagner U, Fischer A. Analysing the causes of chronic cough: relation to diesel exhaust, ozone, nitrogen oxides, sulphur oxides and other environmental factors. J Occup Med Toxicol 2006;1:6.

39. Siegel PD, Saxena RK, Saxena QB, et al. Effect of diesel exhaust particulate (DEP) on immune responses: contributions of particulate versus organic soluble components. J Toxicol Environ Health A 2004;67:221-31.

40. Churg A, Brauer M, del Carmen Avila-Casado M, Fortoul TI, Wright JL. Chronic exposure to high levels of particulate air pollution and small airway remodeling. Environ Health Perspect 2003;111:714-8.

41. Sherwin RP, Richters V, Kraft P, Richters A. Centriacinar region inflammatory disease in young individuals: a comparative study of Miami and Los Angeles residents. Virchows Arch 2000;437:422-8.

42. Gauderman WJ, Avol E, Gilliland F, et al. The effect of air pollution on lung development from 10 to 18 years of age. N Engl J Med 2004;351:1057-67.

43. Kulkarni N, Pierse N, Rushton L, Grigg, J. Carbon 
in airway macrophages and lung function in children. N Engl J Med 2006;355:21-30.

44. Jorgensen H, Svensson A. Studies on pulmonary function and respiratory tract symptoms of workers in an iron ore mine where diesel trucks are used underground. J Occup Med 1970;12:348-54.

45. Wade JF, Newman LS. Diesel asthma, reactive airways disease following overexposure to locomotive exhaust. J Occup Med 1993;35:149-54.

46. Dybdahl M, Risom L, Bornholdt J, Autrup H, Loft $\mathrm{S}$, Wallin H. Inflammatory and genotoxic effects of diesel particles in vitro and in vivo. Mutat Res 2004; 562:119-31.

47. Li N, Nel AE. The cellular impacts of diesel exhaust particles: beyond inflammation and death. Eur Respir J 2006;27:667-8.

48. Garshick E, Laden F, Hart JE, et al. Lung cancer in railroad workers exposed to diesel exhaust. Environ Health Perspect. 2004;112:1539-43.

49. Jarvholm B, Silverman D. Lung cancer in heavy equipment operators and truck drivers with diesel exhaust exposure in the construction industry. Occup Environ Med 2003;60:516-20.

50. Parent ME, Rousseau MC, Boffetta P, Cohen A, Siemiatycki J. Exposure to diesel and gasoline engine emissions and the risk of lung cancer. Am J Epidemiol 2007;165:53-62.

51. Gustavsson P, Evanoff B, Hogstedt C. Increased risk of esophageal cancer among workers exposed to combustion products. Arch Environ Health 1993;48: 243-5.

52. Guo J, Kauppinen T, Kyyronen P, Heikkila P, Lindbohm ML, Pukkala E. Risk of esophageal, ovarian, testicular, kidney and bladder cancers and leukemia among Finnish workers exposed to diesel or gasoline engine exhaust. Int J Cancer 2004;111:286-92.

53. Lee WJ, Baris D, Jarvholm B, Silverman DT, Bergdahl IA, Blair A. Multiple myeloma and diesel and other occupational exposures in Swedish construction workers. Int J Cancer 2003;107:134-8.

54. Brook RD, Brook JR, Urch B, et al. Inhalation of fine particulate air pollution and ozone causes acute arterial vasoconstriction in healthy adults. Circulation 2002;105:1534-6.

55. Ibald-Mulli A, Stieber J, Wichmann HE, Koenig W, Peters A. Effects of air pollution on blood pressure: a population-based approach. Am J Public Health 2001;91:571-7.

56. de Paula Santos U, Braga AL, Giorgi DM, et al. Effects of air pollution on blood pressure and heart rate variability: a panel study of vehicular traffic controllers in the city of Sao Paulo, Brazil. Eur Heart J 2005;26:193-200.

57. Zanobetti A, Canner MJ, Stone PH, et al. Ambient pollution and blood pressure in cardiac rehabilitation patients Circulation 2004;110:2184-9.

58. Mills NL, Tornqvist H, Robinson SD, et al. Diesel exhaust inhalation causes vascular dysfunction and impaired endogenous fibrinolysis. Circulation 2005; 112:3930-6.

59. Block ML, Wu X, Pei Z, et al. Nanometer size diesel exhaust particles are selectively toxic to dopaminergic neurons: the role of microglia, phagocytosis, and NADPH oxidase. FASEB J 2004;18:1618-20.

60. Calderon-Garciduenas L, Reed W, Maronpot R, et al. Brain inflammation and Alzheimer's-like pathology in individuals exposed to severe air pollution. Toxicol Pathol 2004;32:650-8.

61. Margai F, Henry N. A community-based assessment of learning disabilities using environmental and contextual risk factors. Soc Sci Med 2003;56:1073-85.

62. Kilburn KH. Effects of diesel exhaust on neurobehavioral and pulmonary functions. Arch Environ Health 2000;55:11-7.

63. Kim JJ. American Academy of Pediatrics Committee on Environmental Health. Ambient air pollution: health hazards to children. Pediatrics 2004;114:1699-707.

64. Glinianaia SV, Rankin J, Bell R, Pless-Mulloli T, Howel D. Does particulate air pollution contribute to infant death? A systematic review. Environ Health Perspect 2004;112:1365-71.

65. Parker JD, Woodruff TJ, Basu R, Schoendorf KC. Air pollution and birth weight among term infants in California. Pediatrics 2005;115:121-8.

66. Dolk H, Vrijheid M. The impact of environmental pollution on congenital anomalies. Br Med Bull 2003;68:25-45.

67. Watanabe N. Decreased number of sperms and Sertoli cells in mature rats exposed to diesel exhaust as fetuses. Toxicol Lett 2005;155:51-8.

68. Taneda S, Mori Y, Kamata K, et al. Estrogenic and anti-androgenic activity of nitrophenols in diesel exhaust particles (DEP). Biol Pharm Bull 2004;27:835-7.

69. Fredricsson B, Moller L, Pousette A, Westerholm R. Human sperm motility is affected by plasticizers and diesel particle extracts. Pharmacol Toxicol 1993;72: 128-33.

70. Li C, Taneda S, Suzuki AK, Furuta C, Watanabe G, Taya K. Estrogenic and anti-androgenic activities of 4-nitrophenol in diesel exhaust particles. Toxicol Appl Pharmacol 2006;217:1-6.

71. Schaeffer AR. Past and future considerations for heavy duty diesel engine emissions. Environ Health Perspect 2004;112:A727-8.

72. Lanni T. Fine urban and precursor emissions control for diesel urban transit buses. Environ Pollut 2003; $123: 427-37$. 